\title{
DESENVOLVIMENTO E PRODUÇÃO DE BANANEIRA 'GRANDE NAINE' EM DIFERENTES SISTEMAS DE MANEJO PARA A CONVIVÊNCIA COM A SIGATOKA-NEGRA NO VALE DO RIBEIRA-SP ${ }^{1}$
}

\author{
EDSON SHIGUEAKI NOMURA², ERVAL RAFAEL DAMATTO JUNIOR ${ }^{3}$, \\ EDUARDO JUN FUZITANI ${ }^{4}$, LUÍS ALBERTO SAES ${ }^{5}$, SEBASTIÃO DE OLIVEIRA E SILVA ${ }^{6}$
}

RESUMO-Objetivou-se avaliar o desenvolvimento e a produção de bananeira da cultivar Grande Naine submetidos a diferentes sistemas de manejo para a convivência com a Sigatoka-negra no Vale do Ribeira-SP (Brasil). Utilizou-se de mudas de 'Grande Naine' micropropagadas e conduzidas em delineamento inteiramente casualizado, com cinco tratamentos (sistemas de manejo): plantio intercalado; fungicida; desfolha + plantio intercalado; desfolha+fungicida; testemunha e subdividida no tempo (dois ciclos de produção), com oito repetições, considerando uma planta por repetição. Foram avaliados os seguintes parâmetros: altura da planta, diâmetro do pseudocaule, número de folhas ativas no florescimento e na colheita, massa fresca dos frutos comercializáveis, produtividade, número de pencas, número total de frutos, massa fresca total e por frutos da $2^{\mathrm{a}}$ penca, comprimento e diâmetro de frutos da $2^{\mathrm{a}}$ penca. Os dados foram submetidos a análises de variâncias, pelo teste $\mathrm{F}$; e as médias, quando significativas, foram submetidas ao teste de Tukey ( $5 \%$ de probabilidade). Conclui-se que as aplicações de fungicidas foram eficientes para o controle da Sigatoka-negra, com melhores resultados no desenvolvimento, na produção e na qualidade dos frutos da cultivar Grande Naine, porém sem apresentar diferenças quando associados com a desfolha. O plantio intercalado afetou negativamente em todos os parâmetro de desenvolvimento e produção da cultivar Grande Naine.

Termos para indexação: Musa spp., Mycosphaerella fijiensis Morelet, manejo fitossanitário, desfolha, controle químico

\section{DEVELOPMENT AND PRODUCTION OF BANANA 'GRANDE NAINE' IN DIFFERENT MANAGEMENT SYSTEMS FOR ASSOCIATION WITH BLACK SIGATOKA IN VALE DO RIBEIRA REGION (SP)}

\begin{abstract}
This study aimed to evaluate development and production of banana plant 'Grande Naine' under different management systems with black leaf streak presence at Vale do Ribeira, SP (Brazil). For the experiment it was used micropropagated seedlings of 'Grande Naine' banana that was planted in field in a completely randomized design with five treatments (management systems): interspersed planting; fungicide control; defoliation + interspersed planting; defoliation + fungicide control and control, which were subdivided in time (two production cycles), with eight repetition and one plant per repetition. It was evaluated the following parameters: plant height, pseudostem diameter, number of active leaves at blooming and at harvest, marketable fruits fresh weight, productivity, number of hands, number of fruit, total fresh weight and individual fresh weight of the $2^{\text {nd }}$ hand, length and diameter of $2^{\text {nd }}$ hand fruits. Data were submitted to variance analysis by $\mathrm{F}$ test and the significant means were compared by Tukey's test (5\% probability). It can be conclude that fungicides applications were effective for black leaf streak control, showing better results in plants development and production and also in fruit quality of cultivars Grande Naine. No differences were observed when fungicide application was associated with defoliation. The interspersed planting affected negatively all the development and production parameters of cultivar Grande Naine.

Index terms: Musa spp., Mycosphaerella fijiensis Morelet, control disease, defoliation, chemical control.

${ }_{1}^{1}$ (Trabalho 191-14). Recebido em: 17-07-2014. Aceito para publicação em: 18-06-2015.

${ }_{2}^{2}$ Pesquisadores científicos da Agência Paulista de Tecnologia dos Agronegócios - Polo Regional Vale do Ribeira. Rod. BR-116, km 460, Caixa Postal 122, CEP 11900-000, Registro-SP. edsonnomura@apta.sp.gov.br, edufuzitani@apta.sp.gov.br, luisalbertosaes@ apta.sp.gov.br

${ }^{3}$ Professor Visitante da Universidade Federal do Recôncavo da Bahia (URFB). Dr. em Genética e Melhoramento de Plantas. e-mail: ssilva3000@gmail.com

Apoio: CNPq - Conselho Nacional de Pesquisa. Proc. 68.0009/2005-1
\end{abstract}

Rev. Bras. Frutic., Jaboticabal - SP, v. 37, n. 3, p. 644-655, Setembro 2015 


\section{INTRODUÇÃO}

A manutenção da área foliar ativa em bananeiras por maior período de tempo deve ser uma preocupação constante dos produtores de banana. Neste sentido, o controle de doenças foliares, principalmente a Sigatoka-negra (Mycosphaerella fijiensis Morelet), é um dos fatores limitantes no cultivo de bananeiras na maioria dos países produtores (TEIXEIRA et al., 2001). Os sintomas desta doença ocorrem nas folhas, provocando estrias marrons e manchas necróticas negras que reduzem os tecidos fotossintetizantes, ocasionando amarelecimento precoce dos frutos no cacho e, consequentemente, perdas dos rendimentos brutos.

Em fitopatologia, uma doença que ocorre em caráter epidêmico constitui o alvo da epidemiologia, cujo princípio básico preconiza que "a quantidade de doença no campo é determinada pelo balanço entre dois processos opostos: a infecção e a remoção" (BERGAMIN et al., 1995). Assim, a desfolha é uma prática recomendável para restabelecer a sanidade, pois esta permite a redução significativa da fonte de inóculo, o que determina baixos níveis de infecções). Segundo Cordeiro et al. (2011), as folhas cortadas e arrumadas em leiras ou montes na entrelinha do bananal reduzem em até $80 \%$ o potencial de produção de inóculo por estas folhas, reduzindo, consequentemente, a severidade da Sigatoka-negra.

Outro método para a redução da severidade de doenças constitui em interplantios de cultivares na qual ocorrem interações de ordem genética e ecológica entre hospedeiro e patógeno. Além disso, ocorre benefício em virtude do aumento da distância entre plantas suscetíveis e a ação restritiva de expansão do patógeno promovida pelas plantas resistentes, que atuam como barreiras físicas contra a dispersão dos esporos (FINCKH et al., 2000). Segundo estes mesmos autores, as misturas de cultivares oferecem um método rápido para explorar todos os benefícios da pesquisa moderna, promovendo aumento do rendimento de produção e estabilidade, além de contribuir na redução do uso de agrotóxicos e na melhoria da qualidade do produto.

Pelo fato de a Sigatoka-negra ser uma doença muito destrutiva, tem gerado grandes preocupações entre os produtores, técnicos e pesquisadores, principalmente porque a bananicultura é a principal atividade econômica da região do Vale do Ribeira e, por isso, as áreas consideradas livres da doença buscam a todo custo impedir sua introdução, o que implicaria aumento dos custos de proteção e de produção, e perda de um importante diferencial na busca de abertura do mercado externo (BENDINI et al., 2013).

Diante da situação em que se encontra a presença do fungo da Sigatoka-negra, objetivou-se avaliar o desenvolvimento e a produção de bananeira 'Grande Naine' submetida a diferentes sistemas de manejo para a convivência com a doença no Vale do Ribeira-SP.

\section{MATERIAL E MÉTODOS}

O experimento foi conduzido na Agência Paulista de Tecnologia dos Agronegócios - APTA Regional Vale do Ribeira, Pariquera-Açu-SP (243' $31^{\prime \prime}$ S; 4753'48" O), no período de 2010 a 2012, onde o clima é classificado como tropical chuvoso, sem estação seca (Af), segundo a classificação de Köeppen. Dados de uma série de 10 anos (2001- 2011), registrados na APTA Polo Regional do Vale do Ribeira, Pariquera-Açu-SP, mostram que as médias anuais das temperaturas máxima e mínina foram de $26,7^{\circ} \mathrm{C}$ e $17,1{ }^{\circ} \mathrm{C}$, respectivamente, e a pluviosidade média é de 1.715,6 $\mathrm{mm}$ anuais (CIIAGRO, 2013).

O delineamento experimental foi $o$ inteiramente casualizado, com cinco tratamentos (sistemas de manejo): plantio intercalado (PI); fungicida $(\mathrm{F})$; desfolha + plantio intercalado (D+PI); desfolha + fungicida $(\mathrm{D}+\mathrm{F})$; testemunha sem nenhum tratamento adicional e parcela subdivida no tempo (dois ciclos de produção), com oito repetições, considerando-se uma planta por repetição (Figura 1). A área experimental foi instalada em local de ocorrência natural da Sigatoka-negra, utilizandose de mudas de bananeiras micropropagadas em laboratório da cultivar Grande Naine, plantadas no espaçamento de 2,5 x 2,0 m (2.000 plantas.ha $\left.{ }^{-1}\right)$.

As desfolhas fitossanitárias foram realizadas em intervalo de duas semanas, no período chuvoso, e quatro semanas, no período seco ou menos chuvoso. Esta prática correspondeu na eliminação de folhas inteiras ou na parte das folhas que apresentavam os estádios finais de desenvolvimento da Sigatoka-negra (a partir do estádio IV), segundo classificação de Fouré (1985). Imediatamente após o corte, as folhas foram invertidas e amontoadas a cada 15 metros de distância.

No plantio intercalado, adotou-se o consórcio entre duas cultivares de bananeiras, tendo plantas da bananeira 'Grande Naine' (AAA) consorciadas com plantas tolerantes à Sigatoka-negra e de maior porte, a BRS Thap Maeo (AAB), que serviram de bordadura para minimizar a disseminação do inóculo na parcela, de acordo com a Figura 2. 
A avaliação da severidade da Sigatoka-negra iniciou-se quando as bananeiras apresentavam, em média, 1,0 $\mathrm{m}$ de altura e 6 a 8 folhas vivas. $\mathrm{O}$ monitoramento foi realizado semanalmente, em dez plantas por parcela, utilizando o método de Estado da Evolução (EE), adaptado por Fouré (1988) e modificado por Moraes et al. (2005).

Nos tratamentos com aplicação de fungicida, a primeira pulverização foi realizada após a primeira semana de monitoramento para que não houvesse diferenciação entre os tratamentos. As aplicações seguintes de fungicidas foram definidas pela segunda progressão consecutiva da severidade e/ou pelo aumento superior a 200 pontos de uma semana para a outra, determinadas pelo monitoramento semanal da doença nos diferentes sistemas de manejo. Realizaram-se os tratamentos químicos com aplicações alternadas de fungicidas sistêmicos dos grupos químicos triazol e estrobirulina, no período chuvoso e temperaturas elevadas, e com fungicidas do grupo químico benzimidazol, no período menos chuvoso e temperaturas amenas. A partir dos dados de Estado de Evolução da Sigatoka-negra, foi estimada a área abaixo da curva de progresso da doença (AACPD) para cada tratamentos e anos de avaliação, sendo calculada pela fórmula: $\Sigma[((\mathrm{y} 1$ $\left.+\mathrm{y} 2) / 2)^{*}(\mathrm{t} 2-\mathrm{t} 1)\right]$, em que y1 e y2 são duas avaliações consecutivas, realizadas nos tempos $\mathrm{t} 1$ e $\mathrm{t} 2$, respectivamente (CAMPBELL;MADDEN, 1990).

Os gráficos de Estádios de Evolução da Sigatoka-negra e a área abaixo da curva de progresso da doença (AACPD) são apresentados nas Figuras 2 e 3, respectivamente. Os princípios ativos e a semana da aplicação dos fungicidas, em cada tratamento, são apresentados na Tabela 1.

Os cálculos das quantidades de fertilizante de plantio e de formação foram realizados de acordo com os resultados da análise de solo, sendo $270 \mathrm{~kg}$ ha $^{-1}$ de $\mathrm{N}, 110 \mathrm{~kg} \mathrm{ha}^{-1}$ de $\mathrm{P}_{2} \mathrm{O}_{5}$ e $490 \mathrm{~kg} \mathrm{ha}^{-1}$ de $\mathrm{K}_{2} \mathrm{O}$, aplicados de forma homogênea em todas as parcelas experimentais, conforme recomendações de Teixeira et al. (1997). O controle de plantas daninhas foi realizado por meio da aplicação de herbicida à base de glufosinato de amônia $\left(0,5 \mathrm{~L} \mathrm{ha}^{-1}\right)$. Foi mantida somente uma família por plantas (planta mãe, filha e neta), permitindo maior captação, pela planta-mãe, de água e nutrientes fornecidos pelo sistema radicular dos filhos (MOREIRA, 1999).

Durante dois ciclo de produção, avaliaramse os seguintes parâmetros de desenvolvimento das bananeiras: altura da planta (do nível do solo até à roseta foliar) no florescimento, perímetro $(\mathrm{P})$ do pseudocaule no florescimento, a $30 \mathrm{~cm}$ acima do nível do solo, onde se calculou o diâmetro $(\mathrm{D}=\mathrm{P} / \pi)$ e o número de folhas ativas (com mais da metade do limbo verde), no florescimento e na colheita; e parâmetros de produção das bananeiras: massa fresca dos frutos comercializáveis, produtividade (estimados a partir da massa fresca dos frutos comercializáveis e densidade de plantio (2.000 plantas.ha-1)), número de pencas por cacho, número total de frutos, massa fresca da $2^{\mathrm{a}}$ penca, massa fresca por fruto da $2^{\mathrm{a}}$ penca (calculada a partir da divisão da massa fresca da $2^{\mathrm{a}}$ penca pelo número de frutos da $2^{\mathrm{a}}$ penca), comprimento e diâmetro de frutos da $2^{\mathrm{a}}$ penca. Os dados foram submetidos à análise de variância, pelo teste $\mathrm{F}$; e quando significativas, as médias foram comparadas pelo teste de Tukey, a 5\% de probabilidade.

\section{RESULTADOS E DISCUSSÃO}

Os diferentes sistemas de manejo para convivência com a Sigatok-negra não influenciaram na altura das plantas, no florescimento do $1^{\circ}$ ciclo de produção da cultivar Grande Naine, com média de $185,3 \mathrm{~cm}$. No $2^{\circ}$ ciclo, os tratamentos PI e a $\mathrm{D}+\mathrm{PI}$ induziram à redução no porte das plantas, possivelmente pelo sombreamento causado pela cultivar BRS Thap Maeo (Tabela 2). Comparando os dois ciclos, observa-se, no $2^{\circ}$ ciclo, que em todos os sistemas de manejo, eles apresentaram maiores alturas quando comparados com o $1^{\circ}$ ciclo, exceto no PI, em que não se observaram diferenças entres os ciclos. Resultados de pesquisas realizadas em diferentes condições edafoclimáticas mostraram variações em altura da cultivar Grande Naine entre 176,0 e $244,5 \mathrm{~cm} \mathrm{no} 1^{\circ}$ ciclo e de 183,0 a $300 \mathrm{~cm}$ no $2^{\circ}$ ciclo (MENDONÇA et al., 2013; OLIVEIRA et al., 2008; OLIVEIRA et al., 2007; DONATO et al., 2006), concordando com os resultados obtidos em todos os tratamentos.

Semelhante ao ocorrido com a altura das plantas, o diâmetro do pseudocaule não foi influenciado pelos tratamentos no $1^{\mathrm{o}}$ ciclo, apresentando como média de $17,6 \mathrm{~cm}$, bem como no $2^{\circ}$ ciclo, as plantas nos tratamentos PI e a D+PI sofreram redução no diâmetro do pseudocaule (Tabela 2), devido à menor incidência de luminosidade nas folhas, e consequentemente afetou os processos fotossintéticos das plantas. Entre os ciclo produtivos, observaram-se melhores resultados no diâmetro do pseudocaule, no $2^{\circ}$ ciclo, em todos os sistemas de manejo. Na literatura, são relatados valores do diâmetro de pseudocaule da cultivar Grande Naine entre 16,0 e $25,2 \mathrm{~cm}$ no $1^{\circ}$ ciclo e de 20,1 a $33,0 \mathrm{~cm}$ no $2^{\circ}$ ciclo (OLIVEIRA et al., 2007), valores bem próximos dos obtidos em todos os sistemas de manejo 
deste experimento.

De acordo com Moreira (1999), a luz desempenha importante papel na vida da bananeira e exige, para o seu adequado crescimento, receber mais de 1.000 a 2.000 lux, sendo que valores abaixo desta faixa são insuficientes para que ela tenha desenvolvimento normal. Segundo o mesmo autor, se cultivada em local que receba apenas $30 \%$ do limite mínimo de luminosidade, em caráter permanente, a bananeira tende a manter-se por mais tempo em fase vegetativa e a demorar para entrar no processo de diferenciação floral, o que ocorreu na parcela com o plantio intercalado, em que prejudicou o desenvolvimento e a produção das bananeiras.

As parcelas tratadas com fungicidas obtiveram maiores quantidades de folhas ativas no florescimento em comparação com as não tratadas, nos dois ciclos de produção (Tabela 2). Nas parcelas tratadas com fungicidas $(\mathrm{F})$, o número de folhas ativas após o florescimento foi de 9,4 e 11,5 no $1^{\circ}$ e $2^{\circ}$ ciclos, respectivamente. Quando associada à desfolha, a aplicação de fungicida mostrou-se estatisticamente com a mesma eficácia na manutenção de folhas ativas após o florescimento, apresentando 10,1 folhas no $1^{\circ}$ ciclo e 11,9 no $2^{\circ}$ ciclo. Os resultados obtidos neste trabalho são bem próximos aos de Oliveira et al. (2007), que obtiveram 11,5 folhas no $1^{\circ}$ ciclo e 10,6 folhas ativas no florescimento do $2^{\circ}$ ciclo, em Visconde do Rio Branco-MG, onde os bananais foram atacados apenas pelo fungo da SigatokaAmarela (Mycosphaerella musicola Colla). De acordo com Belalcázar et al. (1991), a manutenção de oito folhas foi suficiente para o desenvolvimento normal do cacho até à colheita. Segundo Teixeira et al. (2001), os produtores mantêm, na prática, no mínimo, número igual de folhas ativas e de pencas até à colheita.

No presente trabalho, o plantio intercalado com plantas de maior porte e tolerante à Sigatokanegra (BRS Thap Maeo) afetou diretamente o desenvolvimento da cultivar Grande Naine, pela redução de luminosidade, comprometeu os processos fotossintéticos, além de afetar indiretamente no alongamento do ciclo de produção e na redução da produtividade por área por ano, o que confirmam a declaração de Cordeiro et al. (2011), que plantas sob condições sombreadas aumentam o ciclo, tornam-se mais estioladas e perdem em produção se comparadas a plantas cultivadas a pleno sol e com a Sigatoka-negra sob controle. Além da competição por luminosidade, possivelmente, ocorreu também competição por água e nutrientes entre as duas cultivares, devido ao maior porte da bananeira 'BRS Thap Maeo'.
A quantidade de folhas ativas na colheita seguiu a mesma tendência ao número de folhas ativas no florescimento, na qual os tratamentos $\mathrm{D}+\mathrm{F}$ e $\mathrm{F}$ mantiveram maior número de folhas nos dois ciclos de produção (Tabela 2), contudo abaixo do recomendado por Belalcázar et al. (1991) e Teixeira et al. (2001). Oliveira et al. (2007) obtiveram 2,8 folhas no $1^{\circ}$ ciclo e 4,3 folhas ativas na colheita do $2^{\circ}$ ciclo, sob ataque da Sigatoka-Amarela, no município de Visconde do Rio Branco-MG.

O sistema de manejo com resultados inferiores foi constatado na testemunha, na qual a colheita dos cachos foi antecipada devido à ausência de folhas nas plantas, devido ao ataque intenso da Sigatokanegra, representada pelo maior nível de severidade da doença (Figura 2) e maior somatório da área abaixo da curva de progresso da doença, nos dois anos de avaliação (Figura 3), o que refletiu negativamente na produção e mas qualidades dos frutos (Tabelas 3 e 4). Este resultado é validado com o trabalho realizado por Oliveira et al. (2008), no qual eles observaram que quase todas as folhas foram destruídas pela Sigatoka-negra na colheita da cultivar Grande Naine e cultivado em Rio Branco-AC, chegando ao final dos três ciclos avaliados com menos de uma folha por planta. A maior quantidade de folhas na colheita do $2^{\circ}$ ciclo, no tratamento PI,foi devido ao período do florescimento e do enchimento dos frutos coincidir com o período com condições climáticas desfavoráveis para o desenvolvimento do fungo da Sigatoka-negra (inverno) e com menor pressão de inóculo na área experimental (Figuras 2 e 3), com a consequência da manutenção de folhas nas plantas por maior período de tempo, o que não ocorreu no $1^{\circ}$ ciclo de produção.

A massa fresca dos frutos comercializáveis foi influenciada pelos sistemas de manejo, sendo que a aplicação do fungicida, associada ou não à desfolha, proporcionou maiores massas nos dois ciclos de produção (Tabela 3), indicando que o controle da Sigatoka-negra, até o momento, faz-se necessário por meio de aplicações de fungicidas. Porém, observase que, no $2^{\circ}$ ciclo, apresentou maior massa fresca dos frutos comercializáveis, quando comparado com o $1^{\circ}$ ciclo, em todos os sistemas de manejo. Em trabalho realizado por Gonçalves (2006), no município de Janaúba-MG, com plantio intercalado de diferentes cultivares de bananeira (Prata-Anã, BRS Thap Maeo e Caipira), observou-se redução nos níveis de infecção da Sigatoka-Amarela, em dois ciclos de produção. Além disso, neste trabalho, observou-se que o plantio intercalado com diferentes cultivares não foi eficiente para reduzir a severidade da Sigatoka-negra. 
Calculando-se a produtividade, observouse que, no $1^{\circ}$ ciclo, a produtividade foi maior quando se realizou desfolha associada à aplicação de fungicida $\left(27,2 \mathrm{t} \mathrm{ha}^{-1}\right)$, porém não diferindo, quando comparado, quando aplicado somente o fungicida $\left(22,3 \mathrm{tha} \mathrm{h}^{-1}\right)$. No $2^{\circ}$ ciclo, a produtividade foi estatisticamente superior à do $1^{\circ}$ ciclo, na qual a aplicação de fungicidas e quando associada com desfolha apresentaram índices de produtividade superiores ( $F$ : 35,6 $\mathrm{t} \mathrm{ha}^{-1}$; D+F: 36,5 $\mathrm{t} \mathrm{ha}^{-1}$ ). Estes resultados foram superiores à média nacional $\left(14,3 \mathrm{t} \mathrm{ha}^{-1}\right)$ e paulista $\left(22,6 \mathrm{t} \mathrm{ha}^{-1}\right)$ do ano de 2012 (IBGE, 2014). Como foi observado, o $1^{\circ}$ ciclo não é o momento adequado para avaliar a massa fresca dos frutos comercializáveis e a produtividade, uma vez que este parâmetro pode aumentar nos ciclos subsequentes da cultura (SILVA et al., 2002), o que corrobora os resultados deste trabalho.

Não se observaram no $1^{\circ}$ ciclo diferenças entre os sistemas de manejo para o número de pencas, com média final de 7,4 pencas por cacho. Porém, no $2^{\circ}$ ciclo, o maior número de pencas foi produzido nas plantas cultivadas na testemunha ( 8,5 pencas), sem entretanto diferir estatisticamente dos tratamentos D+F e F (Tabela 3).

O número total de frutos não foi influenciado pelos sistemas de manejo no $1^{\circ}$ ciclo, produzindo em média 102 frutos por cacho, enquanto no $2^{\circ}$ ciclo os sistemas de manejo D+F, F e a testemunha proporcionaram a maior produção de frutos por cacho (132; 134 e 146 frutos, respectivamente), diferindo estatisticamente quando comparado com o $1^{\circ}$ ciclo (Tabela 3 ). A maior quantidade de frutos nos tratamentos com fungicida ( $\mathrm{D}+\mathrm{F}$ e F) refletiu na superioridade em produtividade e na qualidade dos frutos, o que não ocorreu na testemunha, pois apesar de apresentar boa quantidade de pencas e frutos no $2^{\circ}$ ciclo de produção, a massa fresca de frutos comercializáveis e a produtividade foram inferiores aos tratados com fungicidas (Tabela 3), apresentando frutos abaixo do peso e do comprimento e diâmetro fora do padrão de mercado (Tabela 4), devido à antecipação da colheita dos cachos pela ausência de folhas, totalmente destruídas pelo ataque intenso da Sigatoka-negra.

Quando se pretende avaliar a qualidade, bem como a classificação dos frutos produzidos por um bananal, os frutos da $2^{\mathrm{a}}$ penca são utilizados como padrão. Desta forma, para avaliar a qualidade de frutos produzidos sob diferentes sistemas de manejo no bananal, avaliou-se a massa fresca da $2^{\mathrm{a}}$ penca e dos seus frutos. A massa fresca da $2^{\mathrm{a}}$ penca, em ambos os ciclos, foi superior nos tratamentos com uso de fungicidas $(\mathrm{F}$ e $\mathrm{D}+\mathrm{F})$, sendo que a mesma tendência foi observada para a massa fresca por frutos da $2^{\mathrm{a}}$ penca (Tabela 4). Nos demais sistemas de manejo, os cachos foram colhidos antecipadamente, pois as folhas foram rapidamente e totalmente destruídas pelo ataque da Sigatoka-negra, não havendo tempo para o adequado desenvolvimento dos frutos. Quando se comparam os ciclos, o $2^{\circ}$ ciclo apresentou maiores massas frescas da $2^{\mathrm{a}}$ penca, enquanto para a massa fresca por frutos da $2^{\mathrm{a}}$ penca somente não se observou diferença no tratamentos $\mathrm{D}+\mathrm{F}$.

O comprimento e o diâmetro de frutos da $2^{\mathrm{a}}$ penca foram superiores nos tratamentos com a aplicação de fungicidas (D+F e F) no $1^{\circ}$ ciclo de produção (Tabela 4), com médias finais de $19,7 \mathrm{~cm}$ e $32,3 \mathrm{~mm}$ e $19,7 \mathrm{~cm}$ e $32,7 \mathrm{~mm}$, respectivamente. Nos outros sistemas de manejo, os frutos estavam inviáveis para comercialização, com tamanho e calibre abaixo do exigido pelo mercado consumidor, pois a colheita dos cachos foi antecipada devido à ausência de folhas ocasionada pelo ataque intenso do fungo da Sigatoka-negra. O plantio intercalado não reduziu a severidade da Sigatoka-negra; ao contrário, prejudicou o desenvolvimento da planta $\mathrm{e}$, consequentemente, a produção, devido à grande competição por água, luz e nutrientes com a bananeira 'BRS Thap Maeo'.

No $2^{\circ}$ ciclo de produção, o comprimento e o diâmetro de frutos da $2^{\mathrm{a}}$ penca apresentaram a mesma tendência, com superioridade nos tratamentos com aplicação de fungicidas ( $\mathrm{D}+\mathrm{F}$ e $\mathrm{F})$, porém com médias superiores às obtidas no $1^{\circ}$ ciclo (D+F: 20,9 $\mathrm{cm}$ e $33,1 \mathrm{~mm}$; F: $21,2 \mathrm{~cm}$ e $33,5 \mathrm{~mm}$ ) (Tabela 4), porém sem apresentar diferenças entre os ciclos. Nos demais tratamentos, houve prejuízos nestes parâmetros pela antecipação da colheita dos cachos; porém, no $2^{\circ}$ ciclo, os tratamentos apresentaram frutos maiores e diferiram quando comparados com o $1^{\circ}$ ciclo, devido à menor incidência da Sigatokanegra (Figuras 2 e 3) e condições desfavoráveis ao seu desenvolvimento (inverno). De acordo com as normas de classificação do Programa Brasileiro para a Modernização da Horticultura e Produção Integrada de Frutas, nestes tratamentos, os frutos foram classificados na "classe 18" (frutos de 18 a $22 \mathrm{~cm}$ de comprimento) e na categoria "I" (calibre mínimo de $30 \mathrm{~mm}$ ) (PBMH;PIF, 2006).

Diante destes resultados, observou-se que o sistema de plantio intercalado não foi eficiente devido à competição por luz, água e nutriente entre as cultivares, principalmente com a utilização de plantas com maior desenvolvimento ('Thao Maeo'). A desfolha fitossanitária não afetou o controle da doença, visto que nas condições experimentais e pelas características da dispersão da M. fijiensis, 
mesmo com todos os cuidados adotados no experimento, é difícil isolar de forma eficiente as parcelas sem a aplicação de fungicida, sendo qual foi fonte de inóculo da doença aos demais tratamentos.

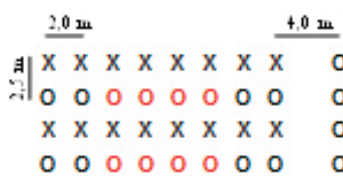

FIGURA 1- Disposição dos tratamentos na área experimental, Pariquera-Açu-SP, 2012. O: 'Grande Naine; X: 'BRS Thap Maeo'; plantas avaliadas( em vermelho).
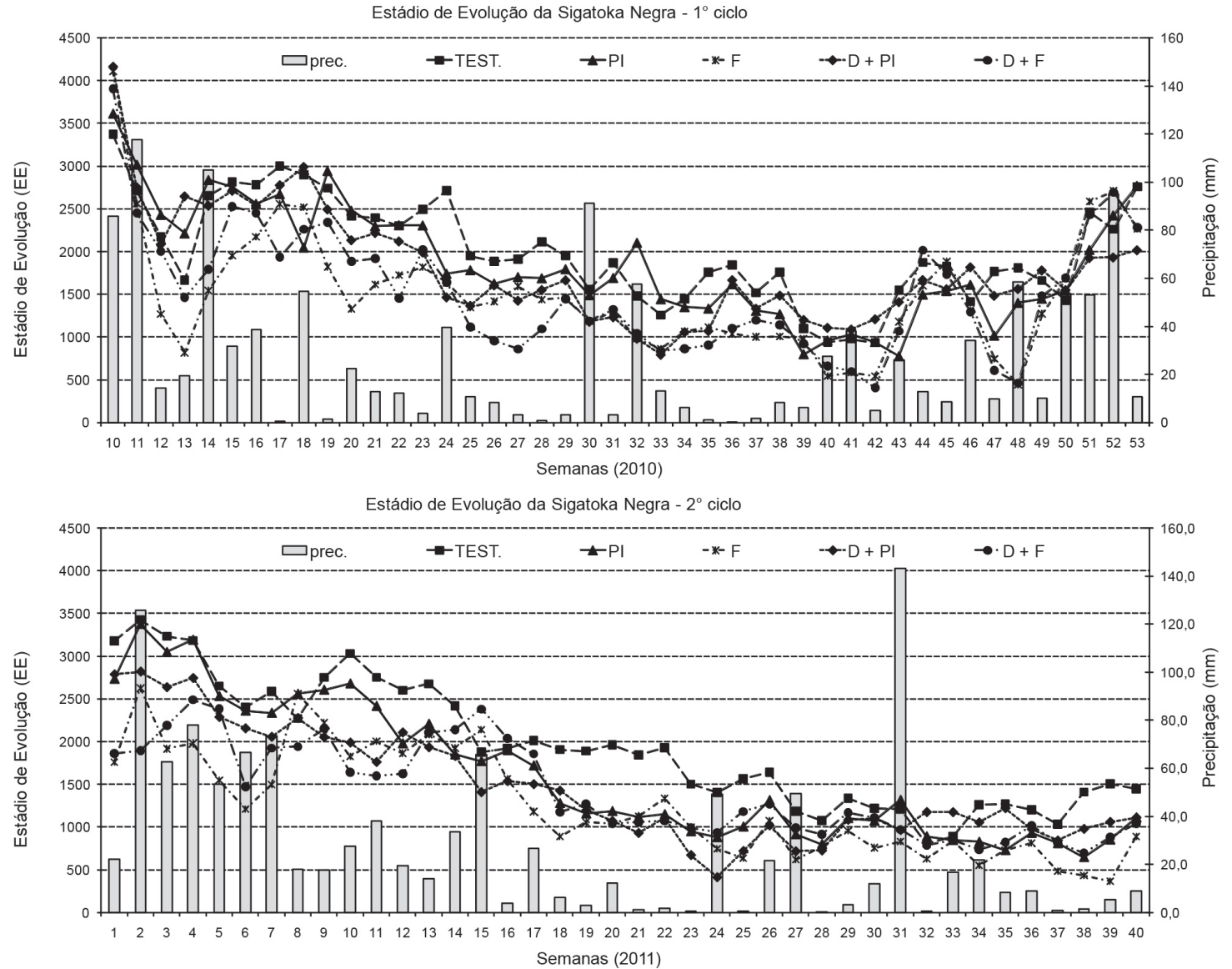

FIGURA 2- Gráfico do Estádio de Evolução da Sigatoka-negra e acúmulo de chuva semanal, PariqueraAçu-SP, 2012. D: desfolha; F: fungicida; PI: plantio intercalado; TEST.: testemunha. 


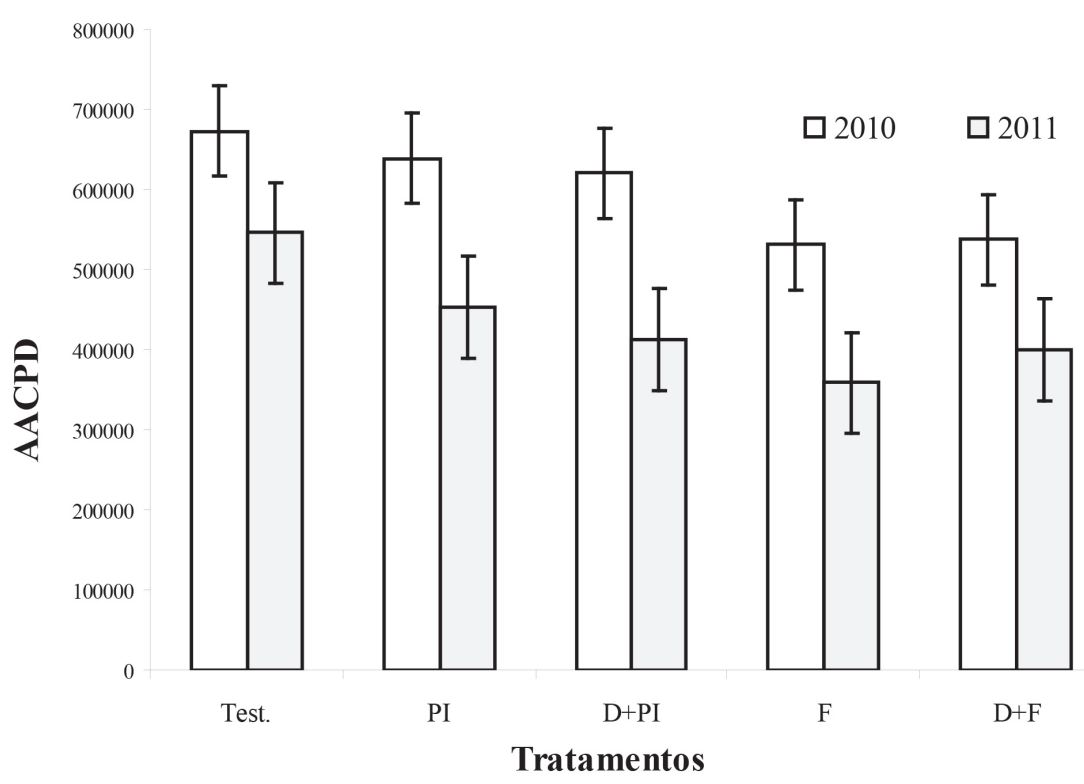

FIGURA 3 - Área abaixo da curva de progresso da doença (AACPD) nos diferentes sistemas de manejo, Pariquera-Açu-SP, 2012. $\mathrm{n}=5$.

TABELA 1- Aplicações alternadas de fungicidas nos diferentes sistemas de manejo, Pariquera-Açu-SP, 2012

\begin{tabular}{|c|c|c|}
\hline Princípios ativos & $\mathrm{F}$ & $\mathrm{D}+\mathrm{F}$ \\
\hline Trifloxistrobina (100 g.L.-1 $)+$ Tebuconazol $(200$ g.L.-1 $)$ & $10 / 2010^{*}$ & $10 / 2010$ \\
\hline Propiconazol (250 g.L.-1) & $\begin{array}{l}16 / 2010 ; 39 / 2010 \\
03 / 2011 ; 41 / 2011\end{array}$ & $\begin{array}{l}16 / 2010 ; 44 / 2010 \\
04 / 2011 ; 40 / 2011\end{array}$ \\
\hline Difenoconazol (250 g.L $\left.{ }^{-1}\right)$ & $22 / 2010 ; 15 / 2011$ & $20 / 2010 ; 15 / 2011$ \\
\hline Tiofanato metílico (200 g. $\left.\mathrm{L}^{-1}\right)$ & $33 / 2010 ; 28 / 2011$ & $30 / 2010 ; 27 / 2011$ \\
\hline Tebuconazol (200 g.L L $\left.^{-1}\right)$ & $09 / 2011 ; 34 / 2011$ & $36 / 2010 ; 09 / 2011 ; 31 / 2011$ \\
\hline Azoxitrobina (250 g.L $\left.\mathrm{L}^{-1}\right)$ & $52 / 2010 ; 23 / 2011$ & $52 / 2010 ; 23 / 2011$ \\
\hline
\end{tabular}

*semana/ano 


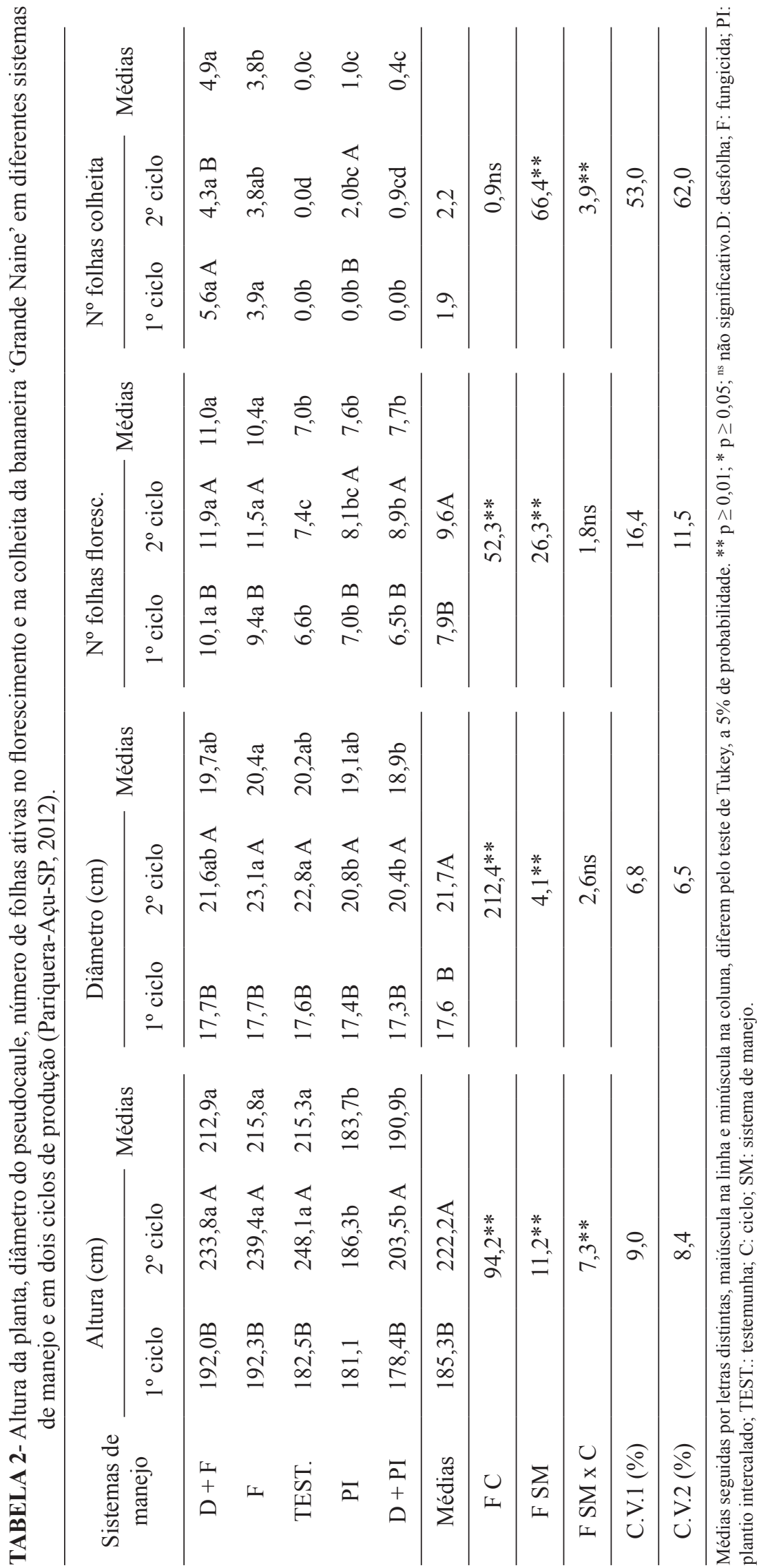




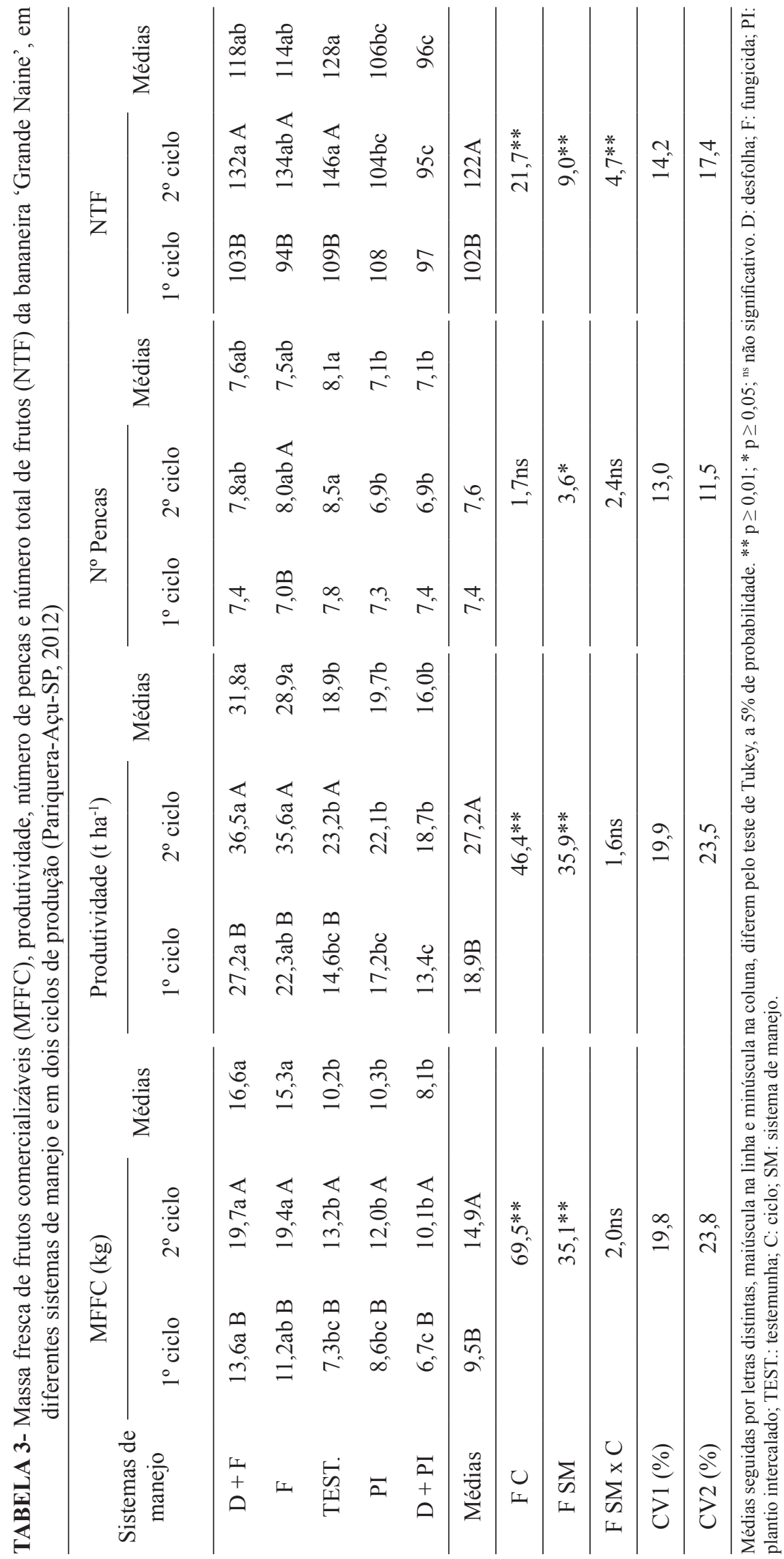




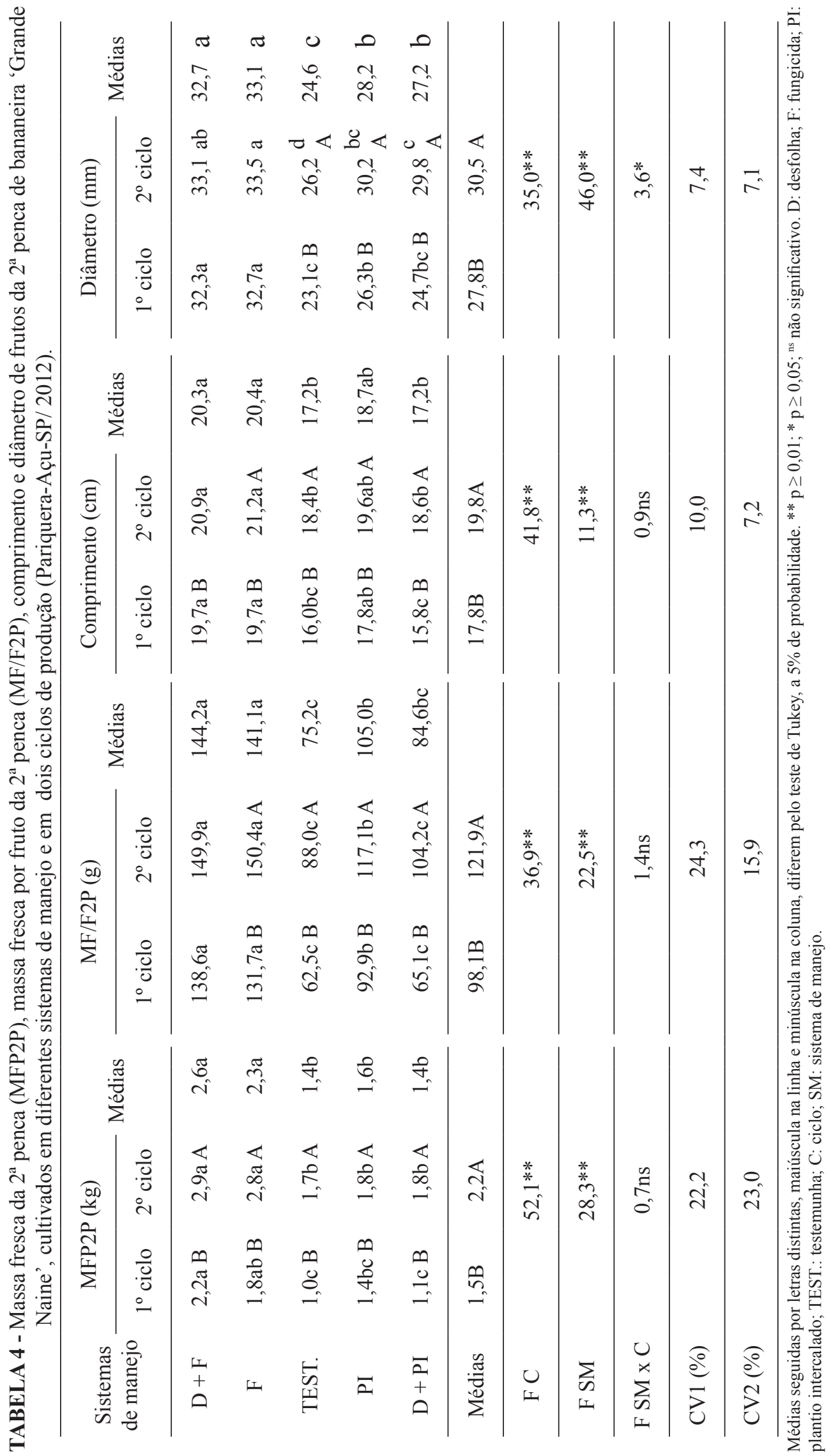




\section{CONCLUSÕES}

Diante das condições experimentais, pode-se concluir que o plantio intercalado afetou negativamente todos os parâmetros de desenvolvimento e da produção da cultivar Grande Naine. Os sistemas de manejo com a utilização de fungicidas associado ou não à desfolha das bananeiras contribuíram para reduzir o impacto negativo da Sigatoka-negra, produzindo frutos de massa e de tamanho adequados para a comercialização.

\section{REFERÊNCIAS}

BELALCÁZAR, C.; TORO-MEZA, J. C.; JARAMILLO-CELIS, R. EI cultivo del plátano en el trópico. Armenia: Feriva, 1991. 376p.

BENDINI, H.N.; MORAES, W.S.; SILVA, S.H.M.G; TEZUKA, E.S.; CRUVINEL, P.E. Análise de risco da ocorrência de Sigatoka-negra baseada em modelos polinomiais: um estudo de caso. Tropical Plant Pathology, Brasília, v. 38, n. 1, p. 35-43, 2013.

BERGAMIN FILHO, A.; KIMATI, H.; AMORIM, L. Manual de fitopatologia: princípios e conceitos. 3.ed. São Paulo: Editora Ceres, 1995. v.1, 919 p.

CAMPBELL, C. D.; MADDEN, L. V. Introduction to plant disease epidemiology. New York: John Willey. 1990.

CIIAGRO - Centro Integrado de Informações Agrometeorológicas. Disponível em: $<$ http://www. ciiagro.sp.gov.br>. Acesso em: 20 abr. 2013.

CORDEIRO, Z.J.M.; MATOS, A.P.; SILVA, S.O. Controle integrado da Sigatoka-negra. In: CORDEIRO, Z.J.M.; MATOS, A.P.; SILVA, S.O. (Ed.). Recomendações técnicas sobre a Sigatoka Negra da bananeira. Cruz das Almas: Embrapa Mandioca e Fruticultura, 2011. p. 81-94.

DONATO, S.L.R; SILVA, S.O.; LUCCA FILHO, O.A.; LIMA, M.B.; DOMINGUES, H.; ALVES, J.S. Comportamento de variedades e híbridos de bananeira (Musa spp.), em dois ciclos de produção no sudoeste da Bahia. Revista Brasileira de Fruticultura, Jaboticabal, v. 28, n. 1, p. 139-144, 2006.
FINCKH, M. R.; GACEK, E.S.; GOYEAU, H.; LANNOU, C.; MERZ, U.; MUNDT, C.C.; MUNK, L.; NADZIAK, J.; NEWTON, A.C.; VALLAVIEILLE-POPE, C.; WOLFE, M.S. Cereal variety and species mixtures in practice, with emphasis on disease resistance. Agronomie, Paris, v. 20, n. 7, p.813-837, 2000.

FOURÉ, E. Black leaf streak disease of bananas and plantains (Mycosphaerella fijiensis Morelet), study of the symptoms and stages of the disease in Gabon. Paris: IRFA, 1985. 23p.

FOURÉ, E. Stratégies de lutte contre la cercosporiose noire dês bananiers et des plantains provoquée par Mycosphaerella fijiensis morelet. l'avertissement biologique au cameroun. evaluation des possibilités d'amélioration. Fruits, Paris, v.43, p. 269-274, 1988.

GONÇALVES, V.D. Interplantio de variedades de bananeira como prática de controle de Sigatoka. 2006. 59 f. Dissertação (Mestrado)- Faculdade de Ciências Agrárias e Veterinárias, Universidade Estadual Paulista, Jaboticabal, 2006.

IBGE - Instituto Brasileiro de Geografia e Estatística. Disponível em: <http://www.sidra.ibge.gov.br>. Acesso em: 18 ago. 2014.

MENDONÇA, K.H.; DUARTE, D.A.S.; COSTA2, V.A.M.; MATOS, G.R.; SELEGUINI, A. Avaliação de genótipos de bananeira em Goiânia, estado de Goiás. Revista Ciência Agronômica, Fortaleza, v.44, n.3 p.652-660, 2013.

MORAES, W.S.; FUKUDA, E.; MODONESEGORLADASILVA, S.H.; MENDONÇA, J.C.; LIMA, J.D. MENDES, C.S. Aplicativo para estimativa biológica da Sigatoka Negra (Mycosphaerella fijiensis Morelet). Fitopatologia Brasileira, Brasília, v.30, n.3, p.193, 2005. Suplemento.

MOREIRA, R.S. Banana: teoria e prática de cultivo. 2.ed. São Paulo: Fundação Cargill, 1999.

OLIVEIRA, C.A.P.; PEIXOTO, C.P.; SILVA, S.O.; LÉDO, C.A.S.; SALOMÃO, L.C.C. Genótipos de bananeira em três ciclos na Zona da Mata Mineira. Pesquisa Agropecuária Brasileira, Brasília, v.42, n.2, p.173-181, 2007. 
OLIVEIRA, T.K.; LESSA, L.S.; SILVA, S.O.; OLIVEIRA, J.P. Características agronômicas de genótipos de bananeira em três ciclos de produção em Rio Branco-AC. Pesquisa Agropecuária Brasileira, Brasília, v.43, n.8, p.1003-1010, 2008.

PBMH \& PIF - Programa Brasileiro para a Modernização da Horticultura e Produção Integrada de Frutas. Normas de classificação de banana. São Paulo: CEAGESP, 2006. 4p. (Documento, 29).

SILVA, S.O.; FLORES, J.C.O; LIMA NETO, F.P. Avaliação de cultivares e híbridos de bananeira em quatro ciclos de produção. Pesquisa Agropecuária Brasileira, Brasília, v. 37, n. 11, p. 1567-1574, 2002.
TEIXEIRA, L.A.J.; RUGGIERO, C.; NATALE, W. Manutenção de folhas ativas em bananeira 'Nanicão' por meio do manejo das adubações nitrogenada e potássica e da irrigação. Revista Brasileira de Fruticultura, Jaboticabal, v. 23, n. 3, p. 699-703, 2001.

TEIXEIRA, L.A.J.; SPIRONELLO, A.; QUAGGIO, J.A.; FURLANI, P. Banana. In: RAIJ, B. van; CANTARELLA, H.; QUAGGIO, J.A.; FURLANI, A.M.C. (Ed.). Recomendações de adubação e calagem para o Estado de São Paulo. 2. ed. rev. Campinas: IAC, 1997.p. 131-132. (Boletim Técnico, 100). 